\title{
Biomechanical engineering comparison of four leaflet repair techniques for mitral regurgitation using a novel 3-dimensional-printed left heart simulator
}

Michael J. Paulsen, MD, ${ }^{\mathrm{a}}$ Mateo Marin Cuartas, MD, ${ }^{\mathrm{a}}$ Annabel Imbrie-Moore, MS,,${ }^{\mathrm{a} b}$ Hanjay Wang, MD, ${ }^{\mathrm{a}}$ Robert Wilkerson, BS, ${ }^{a}$ Justin Farry, BSE, ${ }^{\mathrm{a}}$ Yuanjia Zhu, MD, ${ }^{\mathrm{a}, \mathrm{c}}$ Michael Ma, MD, John W. MacArthur, MD, ${ }^{a}$ and Y. Joseph Woo, MD ${ }^{\mathrm{a}, \mathrm{c}}$

\section{ABSTRACT}

Objective: Mitral valve repair is the gold standard treatment for degenerative mitral regurgitation; however, a multitude of repair techniques exist with little quantitative data comparing these approaches. Using a novel ex vivo model, we sought to evaluate biomechanical differences between repair techniques.

Methods: Using porcine mitral valves mounted within a custom 3-dimensionalprinted left heart simulator, we induced mitral regurgitation using an isolated $\mathrm{P}_{2}$ prolapse model by cutting primary chordae. Next, we repaired the valves in series using the edge-to-edge technique, neochordoplasty, nonresectional remodeling, and classic leaflet resection. Hemodynamic data and chordae forces were measured and analyzed using an incomplete counterbalanced repeated measures design with the healthy pre-prolapse valve as a control.

Results: With the exception of the edge-to-edge technique, all repair methods effectively corrected mitral regurgitation, returning regurgitant fraction to baseline levels (baseline $11.9 \% \pm 3.7 \%$, edge-to-edge $22.5 \% \pm 6.9 \%$, nonresectional remodeling $12.3 \% \pm 3.0 \%$, neochordal $13.4 \% \pm 4.8 \%$, resection $14.7 \% \pm 5.5 \%, P$ $<$ o.01). Forces on the primary chordae were minimized using the neochordal and nonresectional techniques whereas the edge-to-edge and resectional techniques resulted in significantly elevated primary forces. Secondary chordae forces also followed this pattern, with edge-to-edge repair generating significantly higher secondary forces and leaflet resection trending higher than the nonresectional and neochord repairs.

Conclusions: Although multiple methods of degenerative mitral valve repair are used clinically, their biomechanical properties vary significantly. Nonresectional techniques, including leaflet remodeling and neochordal techniques, appear to result in lower chordal forces in this ex vivo technical engineering model. (JTCVS Techniques 2021;10:244-51)

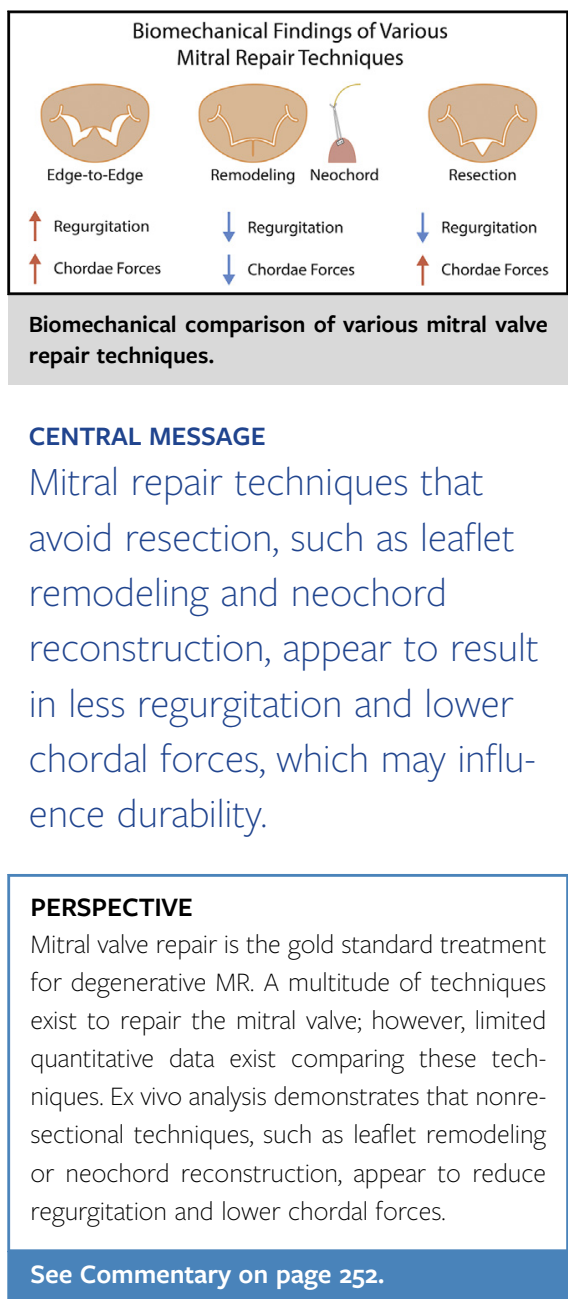

From the Departments of ${ }^{\mathrm{a}}$ Cardiothoracic Surgery, ${ }^{\mathrm{b}}$ Mechanical Engineering, and ${ }^{\mathrm{c} B i o e n g i n e e r i n g, ~ S t a n f o r d ~ U n i v e r s i t y, ~ S t a n f o r d, ~ C a l i f . ~}$

This work was supported by the National Institutes of Health (Grant Numbers R01HL152155 and R01HL089315-01 to YJW), the American Heart Association (17POST33410497 to MJP, 18POST33990223 to HW), the National Science Foundation (GRFP to AIM), and by the Stanford Graduate Fellowship in Science and Engineering (AIM).

Accepted for the 100th Annual Meeting of The American Association for Thoracic Surgery.

Received for publication Sept 21, 2021; accepted for publication Sept 24, 2021; available ahead of print Oct 7, 2021 


\section{Abbreviations and Acronyms \\ FBG $=$ Fiber Bragg Grating \\ $\mathrm{MR}=$ mitral regurgitation \\ 3D $=3$-dimensional}

Video clip is available online.

Degenerative mitral valve regurgitation is the most prevalent cause of valvular heart disease in the Western world, with $3 \%$ of the US population experiencing at least moderate mitral regurgitation (MR). ${ }^{1-5}$ Of patients with at least moderate MR, approximately $10 \%$ develop severe MR requiring surgical correction. ${ }^{6-10}$ Mitral valve repair is the gold standard for treatment of degenerative MR and is superior to valve replacement with regard to patient survival, left ventricular function, and freedom from reoperation. ${ }^{11-20}$ Since being first described approximately 70 years ago, mitral valve repair has become a reproducible and effective therapy. ${ }^{21-27}$

A multitude of techniques have been described, and these can be grouped into several categories, including edge-toedge repair, leaflet resection, nonresectional techniques, and artificial neochord repairs. ${ }^{28-33}$ Although leaflet resection is extremely effective, this method can be more involved and time-consuming than other techniques, and it is also irreversible. ${ }^{34,35}$ Identifying the optimal amount of tissue to resect is challenging, because overzealous resection may result in monoleaflet function, whereas inadequate resection often results in systolic anterior motion of the mitral valve. ${ }^{36,37}$ Nonresectional techniques and neochordoplasty are effective and can be easily reversed, but may not address excessive tissue redundancy; these techniques also leave diseased tissue in place, which may result in recurrent $M R .^{38}$

The existence of so many repair techniques has resulted in limited controlled comparative studies reporting quantitative data supporting one particular repair technique over any other, which may have reduced overall experience and adoption of mitral repair. Several groups have studied the biomechanical properties of various aspects of the mitral valve apparatus, such as annular and leaflet kinetic studies. However, there are limited quantitative biomechanical data comparing individual repair techniques to one another in a standardized and translatable fashion. ${ }^{39-41}$

In this study, we have performed a comprehensive biomechanical comparison of various categories of mitral valve repair, which include edge-to-edge repair, nonresectional leaflet remodeling, leaflet resection, and neochord repair. It is our hope that these analyses lead to improvements in choice of repair strategy to ultimately result in more durable repair results for patients undergoing mitral valve repair.

\section{MATERIALS AND METHODS \\ Left Heart Simulator}

A 3-dimensional (3D)-printed customized and modular left heart simulator, which we have previously described extensively, was used as our testing platform to compare various mitral valve repair techniques (Figure 1, A). ${ }^{42-50}$ Briefly, a 3D printer (M2, Carbon 3D, Redwood City, Calif) was used to rapidly prototype a modular left heart which was mounted to a pulsatile linear actuator (Vivitro Superpump, Vivitro Labs, Victoria, BC, Canada). The device was equipped with pressure and flow sensors to record atrial, ventricular, and aortic pressures as well as transmitral and transaortic flow probes The chamber itself is mostly rigid, with the exception of elastomeric seals and the elastomeric annular mount. The pulsatile pump generates a pressure waveform that propagates throughout the model. To model a physiological heart, which does not have a fixed volume, we employed several multi-element windkessel vessel compliance chambers that could be tuned to modulate or dampen the pressure and flow waveforms to mimic a physiologic heart. A viscoelastic impedance adapter connected to the linear actuator further allowed for modeling physiologic waveforms of ventricular contraction. A 29-mm mechanical aortic valve (St Jude Regent, Abbott Vascular, Lake Bluff, Ill) was used in the aortic position for consistency as homograft valves tend to rapidly degrade in the very saline pump environment. Because no 2 homograft valves are identical, replacing biological tissue based valves should they wear out mid-experiment creates a litany of problems. Thus, we elected to use a mechanical aortic valve, which is infinitely durable and can be cleaned easily between trials. Our reference valve in the mitral position, used for tuning and zeroing the system, was a $28-\mathrm{mm}$ leakless disc valve (Vivitro). With this valve, the system was tuned to generate a cardiac output of 5 liters per minute with a mean arterial pressure of $100 \mathrm{~mm} \mathrm{Hg}$, systolic pressure of $120 \mathrm{~mm} \mathrm{Hg}$, and diastolic pressure of $80 \mathrm{~mm} \mathrm{Hg}$. Normal saline was used as our test fluid for proper conduction and function of the electromagnetic flow meters.

\section{Sample Preparation}

We obtained fresh porcine hearts from a local abattoir and dissected the mitral valve apparatus free from the surrounding tissue, including the chordae tendineae and connected papillary muscles, as well as the annulus and a cuff of left atrial tissue. A total of 7 valves were tested for each experimental condition. Valves of a similar size with intercommissural distances of 34 to $36 \mathrm{~mm}$ were used. A 3D-printed elastomeric sewing ring designed to mimic physiologic annular motion was used to mount the valve inside of our simulator by sewing the left atrial cuff to the elastomeric sewing ring using a continuous locking suture to avoid a purse string effect. The combination of our customized elastomeric sewing ring in conjunction with the preserved cuff of left atrial tissue preserved the native annulus and allowed for physiologic annular motion, which we have previously described in further detail. $^{44,45,51}$ Carbon fiber positioning rods with 3D-printed papillary muscle mounting pads were used to secure the papillary muscles in position by sewing the papillary muscles to the pads with braided polyester suture.

\section{Chordae Force Measurements}

Previously, we developed extremely high-fidelity chordae force sensors using fiber optic sensors called Fiber Bragg Gratings (FBGs), which have been described in depth previously. ${ }^{44}$ Briefly, FBGs are optical fibers with a 

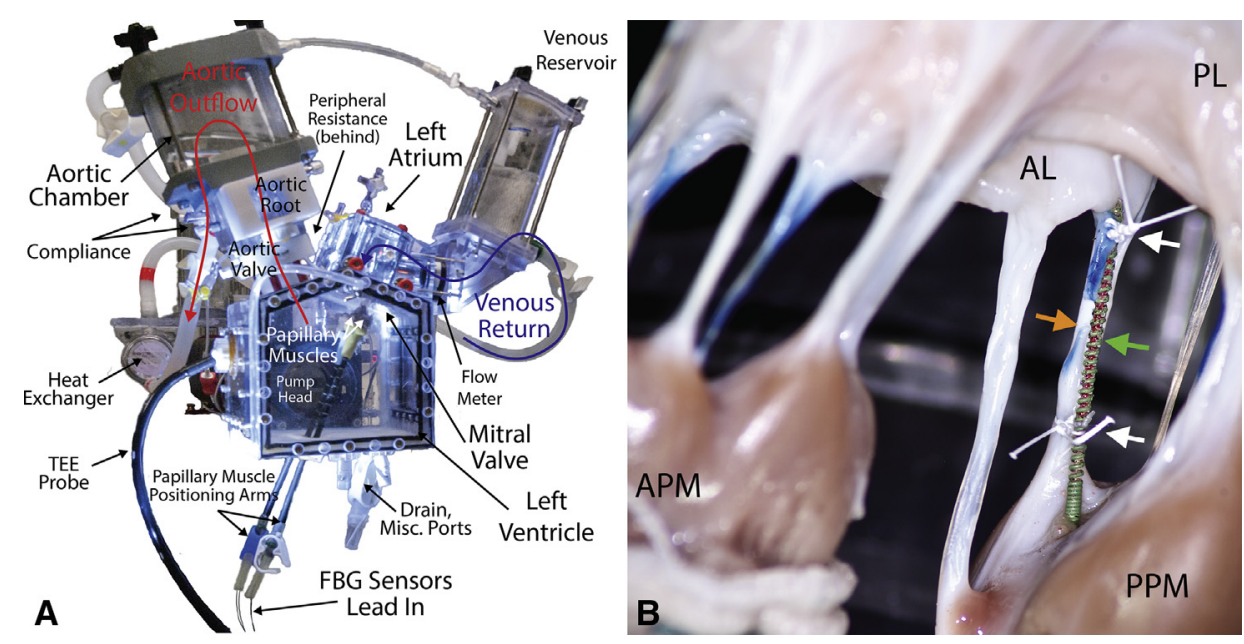

FIGURE 1. A, Schematic of the Stanford left heart simulator in the mitral testing configuration with each component labeled. B, Close-up view of FBG force sensor attached to a chordae tendinea of interest. $P L$, Posterior leaflet; $A L$, anterior leaflet; TEE, transesophageal echo; $A P M$, anterolateral papillary muscle; FBG, fiber Bragg Gratings; $P P M$, posteromedial papillary muscle.

series of spatial period gratings etched within their structures such that they are designed to reflect a particular wavelength of light back to a receiver based upon the spacing of the gratings. When tensile force is applied, the gratings spread farther apart and the wavelength shifts correspondingly; the same is true for compressive force, only opposite. The degree of wavelength shift can be used to measure real-tine strain, which can ultimately be used to calculate dynamic force readings by calibrating the fibers before use. To calibrate the sensors we used an Instron microtester to perform automated tensioning cycles in generating our conversion equations. This calibration process is detailed in our previous work. ${ }^{44}$ The FBGs are encased in an outer shell for stability and also to serve as a structure for attachment to the chordae of interest (Figure 1,B). For each valve, we instrumented 2-4 primary and secondary chordae on both the anterior and posterior leaflets. Of note, higher pressures (primarily systolic) results in higher force measurements. Because a regurgitant valve will by default have lower hemodynamic pressures, it will also have correspondingly lower chordae force measurements. To accurately and consistently compare the force measurements across repair techniques notwithstanding their efficacy for eliminating regurgitation, we normalized each chordae force measurement based on the mean arterial pressure during that particular measurement relative to the baseline pressures using a correction factor.

\section{Study Design and Experimental Setup}

In our ex vivo experimental series, we used a repeated measures design whereby each valve serves as its own positive and negative control. Hemodynamics and forces are first measured in the valve at baseline. Next, isolated P2 prolapse is induced by severing several P2 primary chordae and hemodynamics and forces are again measured. Next, the valves were repaired in series using various repair techniques in an order from least destructive to the valve to more destructive: edge-to-edge suture repair, neochord repair, nonresectional leaflet remodeling, and finally triangular resection (Figure 2, Video 1). The repairs were performed by the same surgeon for each experiment. Hemodynamic parameters and chordae forces were measured after each repair. The valves we tested were unpreserved porcine tissue, and experiments were performed at body temperature; thus, rapid degradation can occur. As a result, we subjected the valves to pulsatile conditions only long enough to zero and calibrate the system before each measurement. Typically, this took less than 5 minutes, or 250 beats per iteration, and was consistent across experimental trials.

\section{Data Acquisition and Statistical Analysis}

Hemodynamic data were recorded with a data acquisition system packaged with the linear pump (Vivitro). To gather FBG sensor data, an optical interrogator was used (Micron Optics si255, Micron Optics, Atlanta, Ga) at an interrogation rate of $1000 \mathrm{~Hz}$. The wavelength measurements were converted into forces using calibration algorithms collected during manufacture of our sensors. MATLAB was used for signal processing, and $\mathrm{R}$ was used for statistical analysis. A linear mixed model fit by the restricted maximum likelihood model was used to compare our groups in a repeated measures fashion. Post hoc testing for pairwise differences was performed using the Bonferroni method. Experimental group (baseline, edge-to-edge, nonresectional, neochord, and resection) was the fixed effects, and valve sample number and order were the random effects for analysis of hemodynamic factors as shown in Table 1. For comparison of chordae forces and a subset of hemodynamic data, we normalized each experimental group to baseline to focus on the comparisons of most interest and to maintain statistical power while also keeping the required sample size to a realistic level. In these analyses, experimental group included the baseline-normalized data for edge-toedge, nonresectional, neochord, and resection. Data are normal and homoscedastic unless otherwise noted and presented as mean \pm standard deviation.

\section{RESULTS}

Hemodynamic parameters and chordae forces for each technique are summarized in Table 1 . Mean and peak gradient did not differ significantly between groups $(P=$ .23 and .16, respectively). Leaflet resection was associated with higher systolic, diastolic, and mean arterial pressures, whereas the edge-to-edge technique was associated with significantly lower pressures, likely due to increased regurgitation $(P<.01$ for all comparisons). Likewise, cardiac output was significantly lower in the edge-to-edge technique compared with the other methods and baseline values $(P<.01)$. Although effective orifice area trended toward 


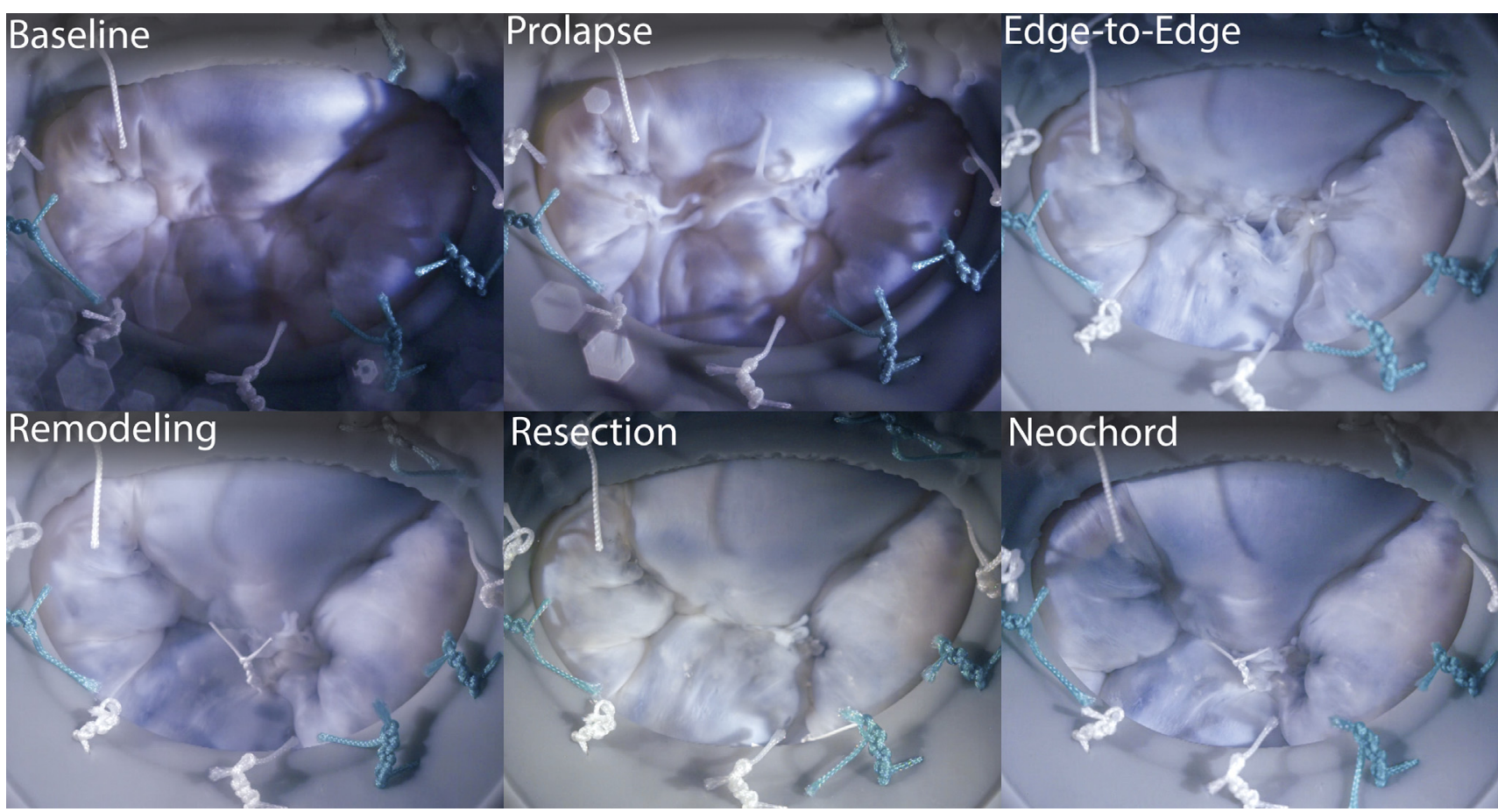

FIGURE 2. En face view of each valve at baseline, after induction of prolapse, and after each repair technique during mid-systole demonstrating leaflet coaptation differences among each technique.

being lowest in the edge-to-edge technique, it did not meet statistical significance $(P=.62)$. With the exception of the edge-to-edge technique, all repair techniques successfully repaired MR and returned regurgitant fraction to baseline levels (baseline $11.9 \% \pm 3.7 \%$, edge-to-edge $22.5 \% \pm$ $6.9 \%$, nonresectional $12.3 \pm 3.0$, resectional $14.7 \pm 5.5$, neochord $13.4 \pm 4.8, P<.01$, Figure $3, A$ ).

Primary chordae forces were minimized using the nonresectional and neochord techniques $(1.03 \pm 0.11$ and $0.86 \pm 0.15$, respectively, relative to baseline) were significantly higher with the edge-to-edge and resectional techniques $(1.33 \pm 0.3$ and $1.32 \pm 0.29$, respectively, $P=$ .002 , Figure $3, B)$. Secondary chordae forces followed a similar pattern and were minimized and closest to baseline

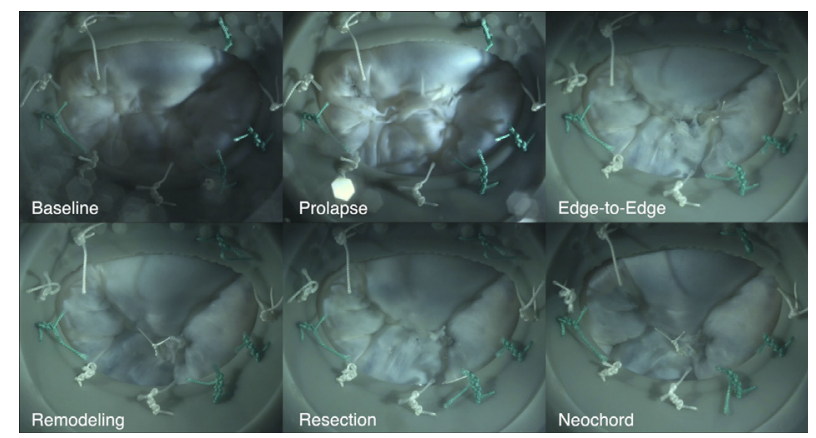

VIDEO 1. En face view of high speed videometric footage highlighting each repair technique. Video available at: https://www.jtcvs.org/article/ S2666-2507(21)00671-4/fulltext. chordae forces in the nonresectional and neochord techniques, whereas the edge-to-edge technique was associated with significantly higher secondary chordae forces (nonresectional: $1.05 \pm 0.19$, neochord: $1.08 \pm 0.16$, edge-toedge: $1.47 \pm 0.34$, Figure 3,C). Leaflet resection resulted in moderately increased secondary chordae forces as compared with baseline (1.22 \pm 0.28$)$.

\section{DISCUSSION}

A plethora of techniques exist for mitral repair in the setting of degenerative MR, and many of these are both reproducible and effective, at least in the immediate perioperative and postoperative time period. Long-term prospective studies directly comparing outcomes and durability of individual mitral valve repair techniques do not exist to our knowledge. Instead, whether or not a particular repair technique is deemed effective and chosen to be used is guided primarily by visual assessment and perioperative echocardiography. As such, the decision of which technique to use in a surgeon's repair strategy is, for the most part, entirely subjective and not based in quantitative data. As a result, early failure after valve repair occurs, and long-term durability of mitral valve repair can likely be improved through the use of more biomechanically optimal repair techniques. In this article, we have demonstrated several important differences in biomechanical parameters that enhances our understanding of various repair techniques and may guide repair strategy choice. 
TABLE 1. Hemodynamic parameters and chordae forces

\begin{tabular}{|c|c|c|c|c|c|c|}
\hline & Baseline & Edge-to-edge & Remodeling & Resection & Neochord & $P$ value \\
\hline Mean gradient (mm Hg) & $1.2 \pm 1.5$ & $2.0 \pm 2.1$ & $1.7 \pm 2.4$ & $1.3 \pm 1.8$ & $1.0 \pm 0.8$ & .23 \\
\hline Peak gradient $(\mathrm{mm} \mathrm{Hg})$ & $5.9 \pm 2.8$ & $9.8 \pm 7.1$ & $6.2 \pm 3.5$ & $6.3 \pm 3.0$ & $4.9 \pm 1.1$ & .16 \\
\hline Mean arterial pressure $(\mathrm{mm} \mathrm{Hg})$ & $100.0 \pm 1.1$ & $92.9 \pm 7.1$ & $103.0 \pm 6.9$ & $102.0 \pm 3.4$ & $101.0 \pm 8.3$ & .01 \\
\hline Systolic pressure $(\mathrm{mm} \mathrm{Hg})$ & $120.0 \pm 2.6$ & $111.0 \pm 7.8$ & $122.0 \pm 7.1$ & $122.0 \pm 2.9$ & $120.0 \pm 9.5$ & $<.01$ \\
\hline Diastolic pressure (mm Hg) & $81.7 \pm 2.0$ & $76.0 \pm 6.4$ & $84.1 \pm 7.4$ & $83.3 \pm 4.9$ & $83.5 \pm 7.7$ & .03 \\
\hline Mean atrial pressure (mm $\mathrm{Hg}$ ) & $8.8 \pm 1.5$ & $10.0 \pm 1.5$ & $9.8 \pm 2.0$ & $8.9 \pm 2.4$ & $9.4 \pm 1.5$ & .33 \\
\hline Heart rate (bpm) & $70.0 \pm 0.0$ & $70.0 \pm 0.0$ & $70.0 \pm 0.0$ & $70.0 \pm 0.0$ & $70.0 \pm 0.0$ & - \\
\hline Pump stroke volume (mL) & $110.0 \pm 0.2$ & $110.0 \pm 0.1$ & $110.0 \pm 0.2$ & $110.0 \pm 0.2$ & $110.0 \pm 0.2$ & - \\
\hline Mitral cardiac output (L/min) & $4.8 \pm 0.3$ & $4.1 \pm 0.4$ & $4.7 \pm 0.2$ & $4.5 \pm 0.3$ & $4.7 \pm 0.2$ & $<.01$ \\
\hline Mitral forward volume (mL) & $75.5 \pm 5.5$ & $75.2 \pm 6.6$ & $76.4 \pm 5.8$ & $75.2 \pm 2.6$ & $77.3 \pm 5.5$ & .84 \\
\hline Mitral closing volume (mL) & $8.6 \pm 2.9$ & $9.9 \pm 3.9$ & $8.7 \pm 2.8$ & $8.9 \pm 3.0$ & $8.9 \pm 3.4$ & $<.01$ \\
\hline Mitral leakage volume (mL) & $0.5 \pm 0.5$ & $7.2 \pm 2.9$ & $0.9 \pm 0.5$ & $2.2 \pm 1.6$ & $1.7 \pm 1.4$ & $<.01$ \\
\hline Regurgitant fraction (\%) & $11.9 \pm 3.7$ & $22.5 \pm 6.9$ & $12.3 \pm 3.0$ & $14.7 \pm 5.5$ & $13.4 \pm 4.8$ & $<.01$ \\
\hline Mitral orifice area $\left(\mathrm{cm}^{2}\right)$ & $6.4 \pm 3.3$ & $4.8 \pm 2.6$ & $6.1 \pm 2.9$ & $6.1 \pm 3.1$ & $6.1 \pm 1.9$ & .62 \\
\hline
\end{tabular}

Data presented as summarized marginal means \pm standard deviation in that they are unconditional over the experimental settings. Sample size $\mathrm{n}=7$. $P$ values refer to partial F-statistics for repair technique from the analysis of variance for the given outcome's fixed effect model. Note that the symbol "-" is used for $P$ values for outcomes that are structurally deterministic. Bold denotes $P \leq .05$.

In terms of residual regurgitation, leaflet resection, neochord reconstruction, and the nonresectional leaflet remodeling techniques all demonstrate comparable efficacy, and return regurgitant fraction to baseline levels. The edge-to-edge technique, which improves regurgitation from the prolapse state, is less effective when compared with the other repair techniques and does not return regurgitant fraction to baseline levels in our experimental model. The edge-to-edge technique also results in significantly higher primary and secondary chordae forces when compared with baseline levels and when compared to the other repair techniques studied, with the exception of leaflet resection, which also seems to result in higher primary chordae forces. These findings may influence the durability of this technique; however, further investigation is necessary before any clinical conclusions can be made. Additional research into this technique is especially important given that many percutaneous technologies that have been developed or are in development rely on the principles behind this repair strategy.

Neochord reconstruction and nonresectional leaflet remodeling resulted in the lowest primary chordae forces

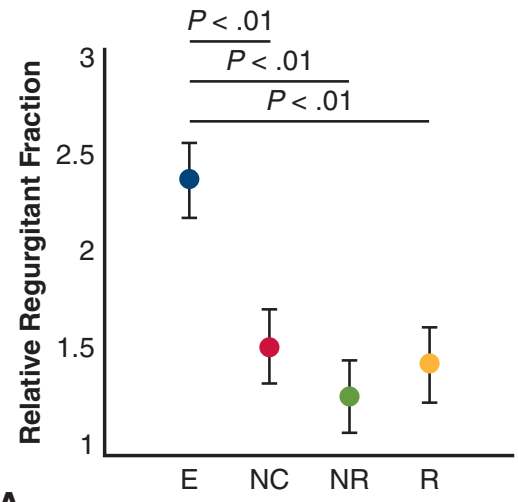

A

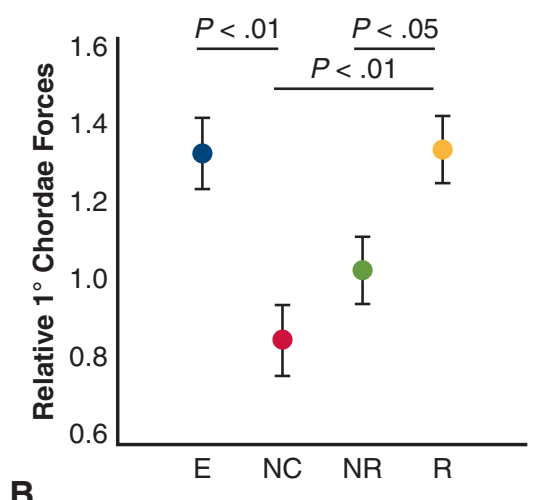

B

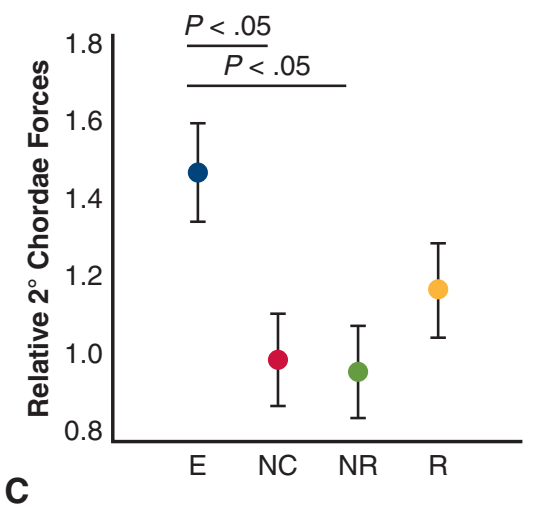

FIGURE 3. A, Regurgitant fraction is significantly higher in the edge-to-edge $(E)$ group relative to the other repair techniques when normalized to baseline values $(P<.01$ for each). B, Primary chordae forces relative to baseline are significantly higher in the edge-to-edge technique versus the neochord technique $(P=.002)$. The resection technique also results in higher primary chordae forces when compared with the neochord $(P=.001)$ and nonrsectional remodeling $(P=.04)$ techniques. $\mathrm{C}$, Secondary chordae forces relative to baseline forces were significantly elevated after edge-to-edge repair versus neochord repair $(P=.03)$ and nonresectional remodeling techniques $(P=.02)$, whereas the other repair techniques resulted in similar secondary chordae forces compared with baseline levels. $N C$, Neochord; $N R$, nonresectional remodeling; $R$, resection. The $P$ values refer to post hoc comparisons with Bonferroni correction from the mixed model. 
when compared with the other mitral repair techniques we tested and resulted in primary chordae forces that trended lower than they were at baseline. This intuitively makes sense in terms of neochord reconstruction, as additional chordae are being added, which essentially increases the denominator, whereas total force, the numerator, remains constant. Why the nonresectional leaflet remodeling technique also results in lower primary chordae forces compared with baseline is less clear, but may be due to restoration of leaflet coaptation, allowing forces to be distributed more evenly to the remaining primary and secondary chordae.

Leaflet resection was extremely effective in eliminating MR, but resulted in significantly higher post-repair primary and secondary chordae forces relative to baseline, despite preservation of all viable chordae during resection. As a result, the total number of remaining chordae was similar after nonresectional leaflet remodeling and leaflet resection, yet forces differed. This may be due to leaflet resection resulting in overall reduced coaptation area compared with the remodeling technique, which ultimately may not allow for optimal distribution of forces throughout the mitral valve apparatus.

Whether these increased chordae forces will result in reduced durability after mitral repair using the edge-to-edge or leaflet resection techniques cannot be definitively ascertained in this study. This conclusion is plausible given the pathophysiology of degenerative MR with chordae elongation and rupture being a common cause of both the initial regurgitation and repair failure. However, further investigation into the effects of chordae forces on repair durability is warranted, and large animal in vivo studies are currently under way.

\section{Study Limitations}

Although our ex vivo study provides a reproducible and controllable environment in which to study the biomechanics of mitral repair, there are limitations to our approach. First, our model does not perfectly recreate interactions between the annulus and ventricle. In addition, the valves we used were healthy porcine valves and prolapse was induced by cutting chordae rather than through native pathological processes resulting in chordae elongation and rupture, although this is an accepted model of MR frequently used experimentally. ${ }^{52,53} \mathrm{We}$ did not use an annuloplasty ring in our experiments, which could influence our results given that annuloplasty is the standard of care in addition to repair techniques. We chose not to include annuloplasty ring so as not to confound our results, but they should be interpreted with this limitation in mind. In addition, healthy porcine valves do not possess the excess tissue typical of valves afflicted by degenerative disease, and as a result, resectional techniques may not be perfectly modeled and the measured chordae forces may be overestimated. MR also results in pathological changes to the structure and function of the left ventricle, namely, that of volume overload. In our system, being composed of a series of rigid chambers, volume is fixed. However, pathological conditions can be modeled through alterations in chamber compliance and the driving waveform of the linear actuator. However, for consistency and to minimize confounding factors, we elected to keep our model tuned to that of a normal physiological ventricle. This is a limitation as the pathological remodeling may imbue important changes on the results of each repair. Likewise, the fixed rigid chamber does not likely generate the physiological helical flow patterns produced by the native hearts' twisting motion. To what degree this may influence the validity of our results is unclear. Our study also does not use a non-Newtonian blood analog, but rather normal saline to facilitate flow meter accuracy. To overcome many of these limitations, the next phase of our study, which is under way, will be studying these repairs in vivo using a large animal model, ideally followed by a clinical study in humans. Lastly, the use of porcine valves rather than human mitral valves is a limitation. However, porcine valves are strikingly similar anatomically in terms of leaflet, annular, and papillary muscle geometry and also have similar chordae tendineae density and cellular composition. ${ }^{54,55}$

\section{CONCLUSIONS}

Our study provides one of the first comprehensive biomechanical comparisons of a wide range of mitral repair techniques and provides concrete, quantitative data that can be used to objectively compare these techniques. We have found that the biomechanical properties of these various repair techniques vary considerably. In particular, we found that techniques that avoid leaflet resection, such as neochordal reconstruction and leaflet remodeling, appear to generate lower chordal forces and reduce regurgitant fraction. It is our hope that this knowledge may inform further study into the durability and function of various repair techniques, which may ultimately help guide repair strategy to result in higher rates of mitral repair and enhanced durability.

\section{References}

\footnotetext{
1. Devereux RB, Jones EC, Roman MJ, Howard BV, Fabsitz RR, Liu JE, et al. Prevalence and correlates of mitral valve prolapse in a population-based sample of American Indians: the Strong Heart Study. Am J Med. 2001;111:679-85.

2. Freed LA, Levy D, Levine RA, Larson MG, Evans JC, Fuller DL, et al. Prevalence and clinical outcome of mitral-valve prolapse. N Engl J Med. 1999;341:1-7.

3. de Marchena E, Badiye A, Robalino G, Junttila J, Atapattu S, Nakamura M, et al. Respective prevalence of the different carpentier classes of mitral regurgitation: a stepping stone for future therapeutic research and development. J Card Surg. 2011;26:385-92.

4. Hayek E, Gring CN, Griffin BP. Mitral valve prolapse. Lancet. 2005;365:507-18.

5. Mozaffarian D, Benjamin EJ, Go AS, Arnett DK, Blaha MJ, Cushman M, et al. Heart disease and stroke statistics-2015 update: a report from the American Heart Association. Circulation. 2015;131:e29-322.

6. Nishimura RA, McGoon MD, Shub C, Miller FA, Ilstrup DM, Tajik AJ Echocardiographically documented mitral-valve prolapse. Long-term follow-up of 237 patients. N Engl J Med. 1985;313:1305-9.

7. Mills P, Rose J, Hollingsworth J, Amara I, Craige E. Long-term prognosis of mitral-valve prolapse. N Engl J Med. 1977;297:13-8.

8. Düren DR, Becker AE, Dunning AJ. Long-term follow-up of idiopathic mitral valve prolapse in 300 patients: a prospective study. J Am Coll Cardiol. 1988;11:42-7.
} 
9. St John Sutton M, Weyman AE. Mitral valve prolapse prevalence and complications: an ongoing dialogue. Circulation. 2002;106:1305-7.

10. Goldstone AB, Patrick WL, Cohen JE, Aribeana CN, Popat R, Woo YJ. Early surgical intervention or watchful waiting for the management of asymptomatic mitral regurgitation: a systematic review and meta-analysis. Ann Cardiothorac Surg. 2015;4:220-9.

11. Gillinov AM, Blackstone EH, Nowicki ER, Slisatkorn W, Al-Dossari G, Johnston DR, et al. Valve repair versus valve replacement for degenerative mitral valve disease. J Thorac Cardiovasc Surg. 2008;135:885-93. 893.e1.

12. Gillinov AM, Cosgrove DM, Blackstone EH, Diaz R, Arnold JH, Lytle BW, et al. Durability of mitral valve repair for degenerative disease. J Thorac Cardiovasc Surg. 1998;116:734-43.

13. Cohn LH, Couper GS, Aranki SF, Rizzo RJ, Kinchla NM, Collins JJ. Long-term results of mitral valve reconstruction for regurgitation of the myxomatous mitral valve. J Thorac Cardiovasc Surg. 1994;107:143-50.

14. David TE, Ivanov J, Armstrong S, Feindel CM, Cohen G. Late results of heart valve replacement with the Hancock II bioprosthesis. J Thorac Cardiovasc Surg. 2001;121:268-77.

15. Sand ME, Naftel DC, Blackstone EH, Kirklin JW, Karp RB. A comparison of repair and replacement for mitral valve incompetence. J Thorac Cardiovasc Surg. 1987;94:208-19.

16. Lee EM, Shapiro LM, Wells FC. Superiority of mitral valve repair in surgery for degenerative mitral regurgitation. Eur Heart J. 1997;18:655-63.

17. Akins CW, Hilgenberg AD, Buckley MJ, Vlahakes GJ, Torchiana DF, Daggett WM, et al. Mitral valve reconstruction versus replacement for degenerative or ischemic mitral regurgitation. Ann Thorac Surg. 1994;58:668-75.

18. Galloway AC, Colvin SB, Baumann FG, Grossi EA, Ribakove GH, Harty S, et al. A comparison of mitral valve reconstruction with mitral valve replacement: intermediate-term results. Ann Thorac Surg. 1989;47:655-62.

19. Enriquez-Sarano M, Schaff HV, Orszulak TA, Tajik AJ, Bailey KR, Frye RL. Valve repair improves the outcome of surgery for mitral regurgitation. A multivariate analysis. Circulation. 1995;91:1022-8.

20. Cohn LH, Kowalker W, Bhatia S, DiSesa VJ, St John-Sutton M, Shemin RJ, et al. Comparative morbidity of mitral valve repair versus replacement for mitral regurgitation with and without coronary artery disease. Ann Thorac Surg. 1988;45:284-90.

21. Goldstone AB, Cohen JE, Howard JL, Edwards BB, Acker AL, Hiesinger W, et al. A "repair-all" strategy for degenerative mitral valve disease safely minimizes unnecessary replacement. Ann Thorac Surg. 2015;99:1983-90.

22. Castillo JG, Anyanwu AC, Fuster V, Adams DH. A near 100\% repair rate for mitral valve prolapse is achievable in a reference center: implications for future guidelines. J Thorac Cardiovasc Surg. 2012;144:308-12.

23. Bakaeen FG, Shroyer AL, Zenati MA, Badhwar V, Thourani VH, Gammie JS, et al. Mitral valve surgery in the US Veterans Administration health system: 10-year outcomes and trends. J Thorac Cardiovasc Surg. 2018;155:105-17.e5.

24. Rosengart TK, Feldman T, Borger MA, Vassiliades TA, Gillinov AM, Hoercher KJ, et al. Percutaneous and minimally invasive valve procedures: a scientific statement from the American Heart Association Council on cardiovascular surgery and anesthesia, council on clinical cardiology, functional genomics and translational biology Interdisciplinary Working Group, and quality of care and outcomes research Interdisciplinary Working Group. Circulation. 2008; 117:1750-67.

25. Davila JC, Glover RP, Trout RG, Mansure FS, Wood NE, Janton OH, et al. Circumferential suture of the mitral ring; a method for the surgical correction of mitral insufficiency. J Thorac Surg. 1955;30:531-60.

26. Lillehei CW, Gott VL, Dewall RA, Varco RL. Surgical correction of pure mitral insufficiency by annuloplasty under direct vision. J Lancet. 1957;77:446-9.

27. Hansen L, Winkel S, Kuhr J, Bader R, Bleese N, Riess F-C. Factors influencing survival and postoperative quality of life after mitral valve reconstruction. Eur J Cardiothorac Surg. 2010;37:635-44.

28. Carpentier A, Adams DH, Filsoufi F. Carpentier's Reconstructive Valve Surgery. 1st ed. Philadelphia, PA: Saunders; 2010.

29. Woo YJ, MacArthur JW. Posterior ventricular anchoring neochordal repair of degenerative mitral regurgitation efficiently remodels and repositions posterior leaflet prolapse. Eur J Cardiothorac Surg. 2013;44:485-9.

30. MacArthur JW, Cohen JE, Goldstone AB, Fairman AS, Edwards BB, Hornick MA, et al. Nonresectional single-suture leaflet remodeling for degenerative mitral regurgitation facilitates minimally invasive mitral valve repair. Ann Thorac Surg. 2013;96:1603-6.

31. Chu MWA, Gersch KA, Rodriguez E, Nifong LW, Chitwood WR. Robotic "haircut" mitral valve repair: posterior leaflet-plasty. Ann Thorac Surg. 2008;85:1460-2.
32. Asai T, Kinoshita T, Hosoba S, Takashima N, Kambara A, Suzuki T, et al. Butterfly resection is safe and avoids systolic anterior motion in posterior leaflet prolapse repair. Ann Thorac Surg. 2011;92:2097-102.

33. Woo YJ. The butterfly takes flight. J Thorac Cardiovasc Surg. 2015;149:1244.

34. McCarthy PM, Herborn J, Kruse J, Liu M, Andrei A-C, Thomas JD. A multiparameter algorithm to guide repair of degenerative mitral regurgitation. J Thorac Cardiovasc Surg. 2020 [Epub ahead of print].

35. Lapenna E, Del Forno B, Amore L, Ruggeri S, Iaci G, Schiavi D, et al. Durability at 19 years of quadrangular resection with annular plication for mitral regurgitation. Ann Thorac Surg. 2018;106:735-41.

36. Brown ML, Abel MD, Click RL, Morford RG, Dearani JA, Sundt TM, et al. Systolic anterior motion after mitral valve repair: is surgical intervention necessary? J Thorac Cardiovasc Surg. 2007;133:136-43.

37. Nazari S, Carli F, Salvi S, Banfi C, Aluffi A, Mourad Z, et al. Patterns of systolic stress distribution on mitral valve anterior leaflet chordal apparatus. A structural mechanical theoretical analysis. J Cardiovasc Surg (Torino). 2000;41:193-202.

38. David TE, David CM, Tsang W, Lafreniere-Roula M, Manlhiot C. Long-term results of mitral valve repair for regurgitation due to leaflet prolapse. J Am Coll Cardiol. 2019;74:1044-53.

39. Ritchie JL. The material properties of the chordae tendineae of the mitral valve: an in vitro investigation [master's thesis]. Georgia Institute of Technology; 2004.

40. Zuo K, Pham T, Li K, Martin C, He Z, Sun W. Characterization of biomechanical properties of aged human and ovine mitral valve chordae tendineae. J Mech Behav Biomed Mater. 2016;62:607-18.

41. Padala M, Sacks MS, Liou SW, Balachandran K, He Z, Yoganathan AP. Mechanics of the mitral valve strut chordae insertion region. J Biomech Eng. 2010;132:081004.

42. Paulsen MJ, Kasinpila P, Imbrie-Moore AM, Wang H, Hironaka CE, Koyano TK, et al. Modeling conduit choice for valve-sparing aortic root replacement on biomechanics with a 3-dimensional-printed heart simulator. J Thorac Cardiovasc Surg. 2019;158:392-403.

43. Paulsen MJ, Imbrie-Moore AM, Baiocchi M, Wang H, Hironaka CE, Lucian HJ, et al. Comprehensive ex vivo comparison of 5 clinically used conduit configurations for valve-sparing aortic root replacement using a 3-dimensional-printed heart simulator. Circulation. 2020;142:1361-73.

44. Paulsen MJ, Bae JH, Imbrie-Moore AM, Wang H, Hironaka CE, Farry JM, et al. Development and ex vivo validation of novel force-sensing neochordae for measuring chordae tendineae tension in the mitral valve apparatus using optical fibers with embedded bragg gratings. J Biomech Eng. 2020;142:0145011-9.

45. Paulsen MJ, Imbrie-Moore AM, Wang H, Bae JH, Hironaka CE, Farry JM, et al. Mitral chordae tendineae force profile characterization using a posterior ventricular anchoring neochordal repair model for mitral regurgitation in a three-dimensional-printed ex vivo left heart simulator. Eur J Cardiothorac Surg. 2020;57: 535-44.

46. Imbrie-Moore AM, Paulsen MJ, Zhu Y, Wang H, Lucian HJ, Farry JM, et al. A novel cross-species model of Barlow's disease to biomechanically analyze repair techniques in an ex vivo left heart simulator. J Thorac Cardiovasc Surg. 2021; 161:1776-83.

47. Imbrie-Moore AM, Paullin CC, Paulsen MJ, Grady F, Wang H, Hironaka CE, et al. A novel 3D-Printed preferential posterior mitral annular dilation device delineates regurgitation onset threshold in an ex vivo heart simulator. Med Eng Phys. 2020;77:10-8.

48. Imbrie-Moore AM, Paulsen MJ, Thakore AD, Wang H, Hironaka CE, Lucian HJ, et al. Ex vivo biomechanical study of apical versus papillary neochord anchoring for mitral regurgitation. Ann Thorac Surg. 2019;108:90-7.

49. Zhu Y, Imbrie-Moore AM, Paulsen MJ, Priromprintr B, Wang H, Lucian HJ, et al. Novel bicuspid aortic valve model with aortic regurgitation for hemodynamics analysis using an ex vivo simulator. J Thorac Cardiovasc Surg. 2020 [Epub ahead of print].

50. Zhu Y, Imbrie-Moore AM, Paulsen MJ, Priromprintr B, Park MH, Wang H, et al. A novel aortic regurgitation model from cusp prolapse with hemodynamic validation using an ex vivo left heart simulator. J Cardiovasc Transl Res. 2021;14:283-9.

51. Imbrie-Moore AM, Park MH, Paulsen MJ, Sellke M, Kulkami R, Wang H, et al. Biomimetic six-axis robots replicate human cardiac papillary muscle motion: pioneering the next generation of biomechanical heart simulator technology. $J$ R Soc Interface. 2020; 17:20200614.

52. Leroux AA, Moonen ML, Pierard LA, Kolh P, Amory H. Animal models of mitral regurgitation induced by mitral valve chordae tendineae rupture. J Heart Valve Dis. 2012;21:416-23.

53. Li B, Cui Y, Zhang D, Luo X, Luo F, Li B, et al. The characteristics of a porcine mitral regurgitation model. Exp Anim. 2018;67:463-77. 
54. Crick SJ, Sheppard MN, Ho SY, Gebstein L, Anderson RH. Anatomy of the pig heart: comparisons with normal human cardiac structure. J Anat. 1998;193(Pt 1):105-19.

55. Millington-Sanders C, Meir A, Lawrence L, Stolinski C. Structure of chordae tendineae in the left ventricle of the human heart. J Anat. 1998;192(Pt 4):573-81.
Key Words: biomechanics, chordae forces, ex vivo model, leaflet remodeling, leaflet resection, mitral valve repair, neochord 